\title{
Fatigue Performance of Biodegradable Magnesium-Calcium Alloy Processed by Laser Shock Peening for Orthopedic Implants
}

\author{
M.P. Sealy ${ }^{a}$, Y.B. Guo ${ }^{a^{*}}$, R.C. Caslaru ${ }^{a}$, J. Sharkins ${ }^{b}$, D. Feldman ${ }^{b}$ \\ Dept. of Mechanical Eng., The University of Alabama, Tuscaloosa, AL 35487, USA \\ Dept. of Biomedical Eng., University of Alabama at Birmingham, Birmingham, AL 35294, USA
}

\begin{abstract}
Permanent orthopedic implants made from titanium, stainless steel, or cobalt-chromium alloys cause stress shielding and lead to secondary surgery. Biodegradable magnesium-calcium $(\mathrm{MgCa})$ alloys have the potential to minimize stress shielding as well as eliminate the need for secondary surgery. The critical technical challenge is that magnesium degrades rapidly in the human body. In order to slow the corrosion rate, surface treatments such as laser shock peening (LSP), shot peening, or burnishing have been reported in literature. Each of these surface treatments uniquely alters the surface integrity and consequent fatigue life. Even though surface treatments may be effective at slowing corrosion rates, it is important to ensure that they do not shorten fatigue life. The purpose of this study was to (1) develop a laser shock peening (LSP) surface treatment of a curved surface that adjusts the surface integrity of a $\mathrm{MgCa}$ alloy by varying the peening overlap ratio and (2) determine the effect of LSP on the fatigue life. Surface integrity was characterized by topography, microstructure, and microhardness. Fatigue life of laser peened and unpeened samples were measured by rotating bending fatigue tests. It was found that LSP increased the fatigue life of the peened MgCa samples. Implementing LSP at high overlap ratios reduced the surface pile-up which resulted in a higher fatigue life. The fractured surfaces of the peened samples exhibited striation patterns which were more pronounced at higher peening overlap ratios.
\end{abstract}

Keywords: surface treatment, fatigue, magnesium, biodegradable implant, laser shock peening

\footnotetext{
* Corresponding author. Tel.: +1 205348 2615; Fax: +1 2053486419.

E-mail address: yguo@eng.ua.edu (Y.B. Guo).
} 


\section{Introduction}

There exists a great need to develop an innovative manufacturing process that can control the performance of a degradable metal implant for orthopedic applications. The problem with the current metallic orthopedic implants made from titanium, stainless steel, or cobalt-chromium alloys is that they cause stress shielding. It also often leads to a second removal or revision surgery. Many surgeons opt not for a second surgery because the risks outweigh the benefits. Degradable materials eliminate the need for a second surgery. A promising biodegradable metal is magnesium-calcium ( $\mathrm{MgCa})$ alloy. The critical technical challenge is that magnesium $(\mathrm{Mg})$ degrades too fast in human body fluid. One promising method to slow the corrosion of $\mathrm{Mg}$ is by surface treatments such as laser shock peening (LSP) [1]. Even though LSP has proven capable of slowing corrosion, the effect of a micro-dented surface on the fatigue performance of a $\mathrm{MgCa}$ alloy remains unknown.

Fatigue is a damage process by which irreversible changes are made to a material by repeated application of load [2]. Fatigue damage typically initiates in the form of cracks on the external surface of a part [3]. Corrosion and wear can accelerate fatigue damage mechanisms. Therefore, the surface integrity of a part is of critical importance for high cycle fatigue applications as it can directly influence an implant's fatigue life. Aspects of surface integrity that are important to fatigue life include but are not limited to surface roughness, microhardness, and residual stress.

Mechanical surface treatments such as burnishing and shot peening are effective methods to improve the fatigue life. Surface treatments alter the mechanical properties of the top layer of a surface in a way that may prevent crack initiation and retard crack propagation. Determining the correct surface treatment depends on the material being processed [3]. For magnesium, there 
is a delicate balance between imparting sufficient compressive residual stress while maintaining a surface free of micro-cracks which would ultimately shorten fatigue life. While a rough surface is generally favorable for promoting bone ingrowth and healing, that same indented surface may serve as a crack initiator that would detrimentally affect fatigue performance.

For shot peening, the fatigue life of magnesium alloys has shown to be either enhanced or diminished depending on the peening pressure, bead type, alloy, etc. On the other hand, laser shock peeing (LSP) with a large spot size on the order of $\mathrm{mm}$ is well known to improve the fatigue life of aluminum and titanium alloys [4-8]. In these cases, there is a negligible effect on the surface topography. For micro laser shock peening, where the spot size is on the order of 10's and 100's of microns, the shock wave produced by the ablation process is no longer a planar front but rather a spherical wave that results in a sizable surface topography in the form of micro-dents. It is unknown if these dents act as notches (i.e. crack initiators) or if the compressive residual stress will prevent crack formation and slow propagation. The purpose of this study is to determine if (1) micro-dents produced by LSP on a degradable Mg alloy act to shorten fatigue life or (2) does the enhanced strength and hardness imparted by LSP increase the fatigue life.

The focus of this research is to (1) design a surface modification process to control the performance of a degradable metal implant within a desired range, (2) measure the resulting surface integrity imparted by the process, (3) evaluate the fatigue performance of the surface, and (4) understand the relationships between process, surface integrity, and performance. The end result for this technology is to develop the next generation of orthopedic implants that can be tailored to degrade in a few months or a few years depending on what each patient needs. 


\section{Effect of Mechanical Surface Treatment on Fatigue}

In surface treatment processes like shot peening or laser shock peening (LSP), the resulting surface topography can take the form of micro-dents or notches. Notches are well known for acting as stress concentrators that reduce fatigue life [9]. In fact, notches are often intentionally added to fatigue test samples in order to concentrate stress at a specific location so that failure occurs at the specified location. Notches can have many different shapes, e.g. $\mathrm{v}$-shaped grooves such as those on a screw or dents like the ones observed on a golf ball. Aspect ratios produced by mechanical surface treatments can be relatively smooth (100:1), such as the case in burnishing, or be more closely towards equiaxial (1:1), which is possible with shot peening or micro-indenting.

As for magnesium alloys, the effect of surface treatments on magnesium alloys exists in literature but is limited to mostly AZ-xx alloys since it is a structural grade material and a few others, e.g. $\mathrm{MgCa} 0.8$ and $\mathrm{Mg}-10 \mathrm{Gd}-3 \mathrm{Y}$. There is limited literature on the fatigue behavior of $\mathrm{MgCa}$, especially after surface treatments.

The effect of notches on fatigue life is typically detrimental [9]. Kannan et al. showed that the mechanical integrity of AZ91 in simulated body fluid (SBF) decreased by approximately $50 \%$ when the samples contained a notch with an aspect ratio of 1.15:1 [10]. The authors quantified mechanical integrity as the ratio of the failure stress in SBF to the failure stress in air.

A smooth (un-notched) sample had mechanical integrity of 0.83 while a v-shaped notched sample was approximately 0.44 . In order to overcome the effect of notches, highly compressive residual stresses are desired that prevent crack formation and inhibit crack propagation. Therefore it is important to find the "right" surface treatment that slows degradation without sacrificing mechanical integrity and fatigue life. 
Von der Höh et al. investigated the effects of different surface treatments of $\mathrm{MgCa} 0.8$ on the degradation behavior in rabbits [11]. The authors claimed all implants were well tolerated. The surfaces were as-turned, sand blasted, and threaded. The threaded and sand blasted implants exhibited emphysema, or abnormal air cavities within the tissue, while the smooth implants showed no signs of emphysema. Interestingly, the threaded implants produced the strongest bone formation indicating that the rougher surface provided more area for bone to adhere, thus increasing the healing rate. However, the sand blasted and threaded implants observed faster structural loss which could pose problems for fatigue loading applications.

Fouad et al. showed that ball burnishing AZ31 increased the endurance limit in rotating bending to $100 \mathrm{MPa}$ compared to the electropolished surface at $40 \mathrm{MPa}$ [12]. Analogous to fatigue, Fouad and Batanouny showed the wear rate (pressure load $=0.3$ bar, rotation speed $=150 \mathrm{RPM}$, time $=30 \mathrm{~min})$ of surfaces treated by shot peening, swaging, and ball burnishing reduced by more than $10 \%$ in some cases over the wrought and as-cast parts [13].

Hilpert and Wagner investigated the effect of mechanical polishing, shot peening, and roller burnishing on the corrosion fatigue behavior of high strength AZ80 in rolling fatigue tests [14]. They showed that mechanical polishing and shot peening improved the fatigue performance in air; however, no improvement was observed in a $\mathrm{NaCl}$ solution (Fig. 1). The roller burnished surface exhibited the best fatigue performance in the $\mathrm{NaCl}$ solution, and the authors attributed this observation to the smooth surface and compressive residual stress that accompanies burnishing. For shot peening, the steel beads had better fatigue performance compared to glass beads. 


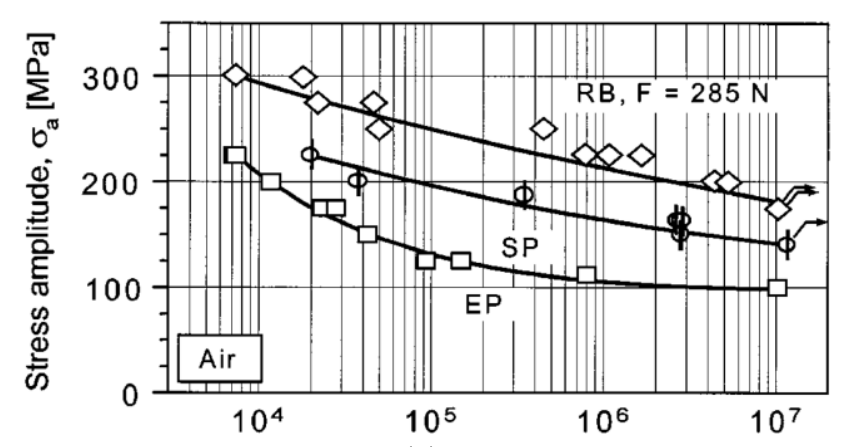

(a)

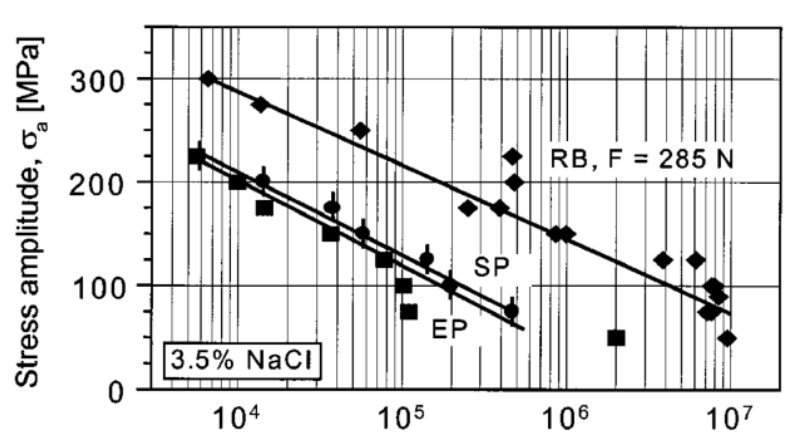

(b)

Fig. 1 Rotating bending $(\mathrm{R}=-1) \mathrm{S}-\mathrm{N}$ curves of AZ80 processed by roller burnishing $(\mathrm{RB})$, shot peening (SP), and electropolishing (EP) in (a) air and (b) $3.5 \% \mathrm{NaCl}$ solution [14].

Bhuiyan et al. studied the effect of shot peening, micro-peening, and barrel processing on fatigue life of AZ61 [15]. Micro-peening was defined as shot peening with $20 \mu \mathrm{m}$ to $30 \mu \mathrm{m}$ size beads. For comparison, regular shot peening used $0.425 \mathrm{~mm}$ size beads. Barrel processing involves using a rotating drum filled with steel beads that alter the surface of a component.

Shot peened samples had the worst fatigue performance, see Fig. 2. The fatigue strength decreased by approximately $30 \%$ compared to the as-polished samples. The authors attribute this to the poor surface quality caused by the peening process and further state that the induced compressive residual stress was not sufficient enough to offset crack propagation. Micro-peened and barrel processed samples exhibited a $15 \%$ higher fatigue strength than as-polished samples. The authors claim the effect of compressive residual stress was capable of outweighing the detrimental effect of micro-cracks produced during the surface treatment process; however, residual stress measurements were not provided and microhardness data was given instead. 


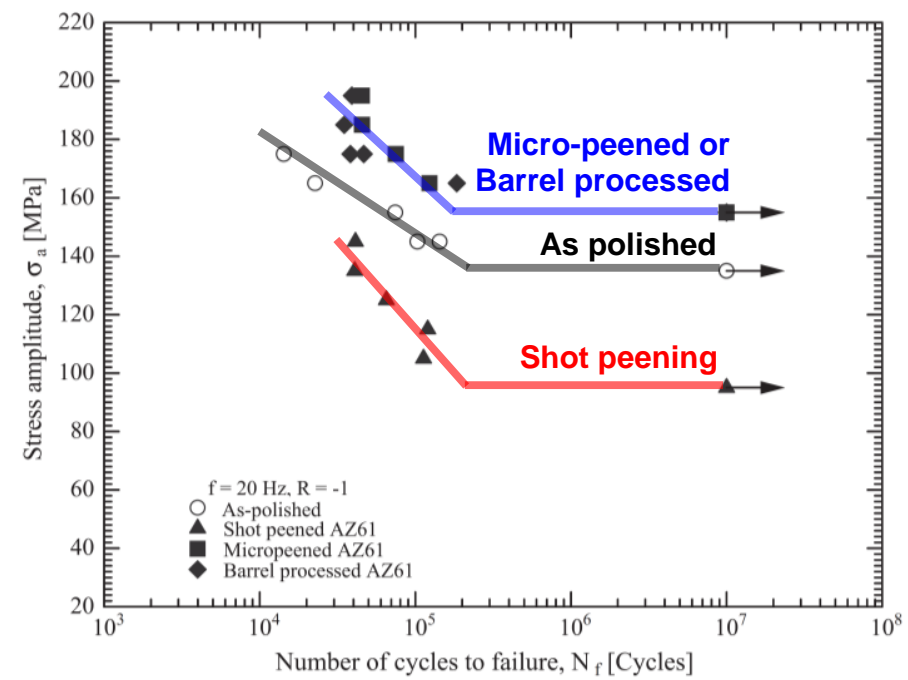

Fig. 2 Rotating bending S-N curves of AZ61 processed by shot peening, micro-peening, and barrel processing. Modified from [15].

Secondary peening has been suggested as a way to induce more compressive residual stress while concurrently minimizing the surface roughness. Dindorf and Müller studied the fatigue behavior of AZ91 after shot peening followed by additional secondary shot peening with glass beads [16]. Their results show that secondary peening did not significantly influence the endurance limit.

Liu et al. explored the effect of varying the Almen peening intensity on the fatigue performance of Mg-10Gd-3Y [17]. Results showed that the fatigue life reached a saturation point whereby an increase in the Almen intensity beyond $0.2 \mathrm{mmN}$ would not further increase the fatigue life, see Fig. 3. Beyond this critical value for Almen intensity, $0.2 \mathrm{mmN}$ in this study, the fatigue life decreased. This indicates there are optimum peening conditions that maximize benefits for fatigue life. Results also showed that shot peening was more beneficial for as-extruded parts compared to as-cast parts. 


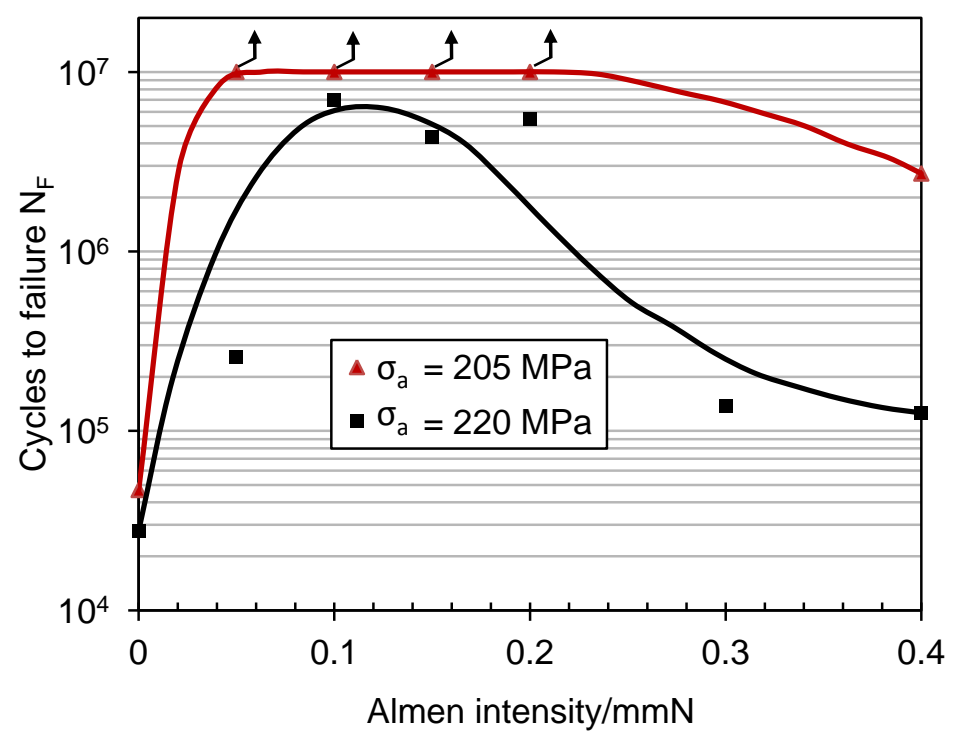

Fig. 3 Fatigue life versus Almen intensity for as-extruded Mg-10Gd-3Y at different stress amplitudes. Modified from [17].

Zhang et al. investigated the effect of different shot peening media, such as glass beads, Zirblast $\mathrm{B} 30$, and $\mathrm{Ce}-\mathrm{ZrO}_{2}$ on the fatigue performance of $\mathrm{AZ80}$. Improvements up to $75 \%$ in fatigue strength were observed; see Fig. 4(a). $\mathrm{Ce}-\mathrm{ZrO} 2$ shots had the highest improvement on fatigue strength as well as the lowest roughness and the highest maximum compressive residual stress. The glass and Zirblast B30 beads exhibited a well-defined Almen pressure range in which the benefit to fatigue life was maximized, between $0.1 \mathrm{mmN}$ and $0.2 \mathrm{mmN}$ in that study; see Fig. 4(b). Outside this region, fatigue life drop more than 1 order of magnitude. 


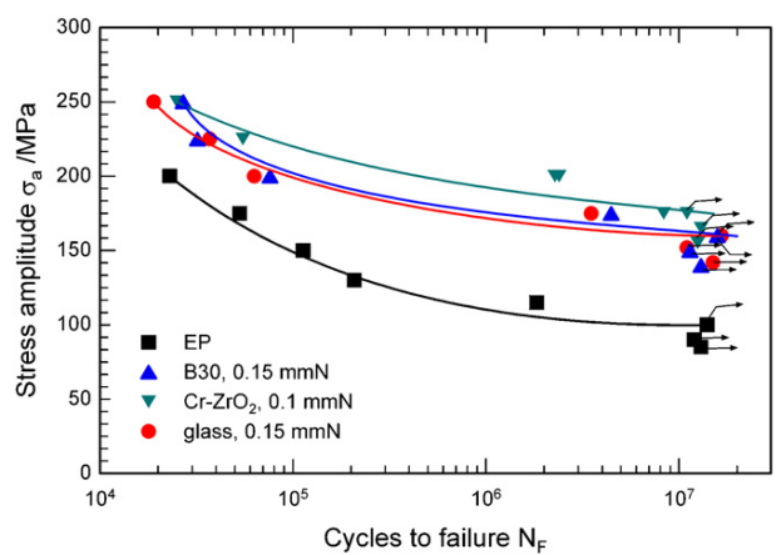

(a)

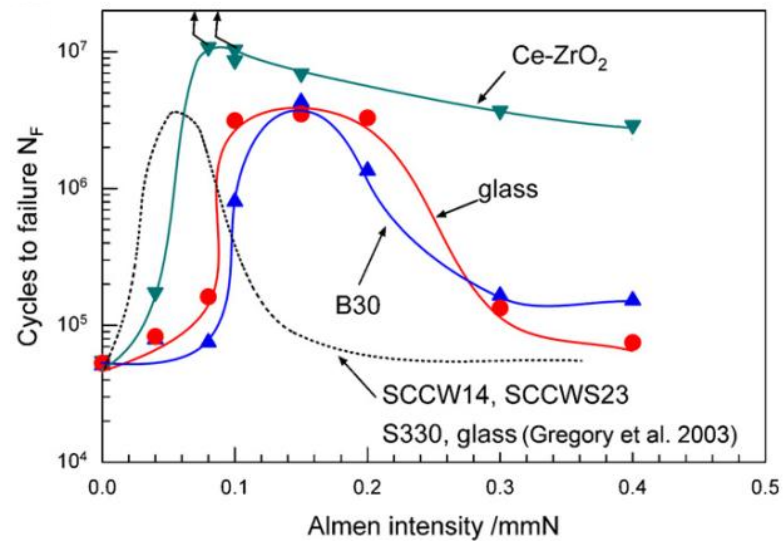

(b)

Fig. 4 Rotating bending fatigue performance of AZ80 shot peened by various peening media: (a) S-N curve (b) fatigue life versus Almen intensity [16].

In contrast, Zinn and Scholtes showed that shot peening AZ31 reduced the fatigue strength, see Fig. 5 [18]. Small cracks on the surface induced by shot peening were said to have caused the reduction. This further indicates appropriately choosing the right peening conditions for each $\mathrm{Mg}$ alloy can determine if fatigue properties will be enhanced or diminished.

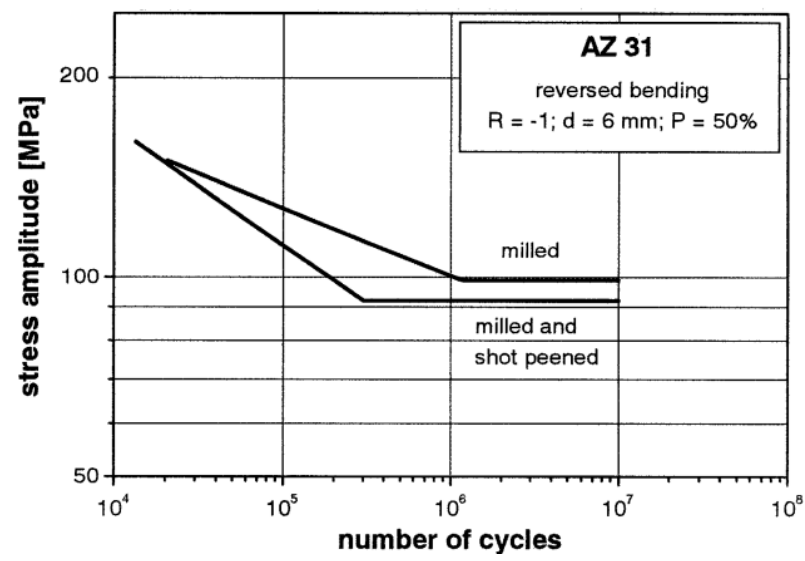

Fig. 5 Rotating bending S-N curve of as-milled and shot peened AZ31 [17]. 


\section{Fatigue Sample Preparation}

Cylindrical bars of a $\mathrm{MgCa}$ alloy $(0.8 \mathrm{wt} \% \mathrm{Ca})$ for orthopedic applications that were $12.7 \mathrm{~mm}$ in diameter and $254 \mathrm{~mm}$ in length were turned to $9.5 \mathrm{~mm}$ and sectioned into thirds. The center region of each sample was further turned into a dog bone shape giving it a notch with a diameter $7.6 \mathrm{~mm}$ in the center, see Fig. 6 . The notch is designed to exert some level of control over where the sample will break. Ideally, the sample will break in the laser shock peened region. The center of the sample was laser shock peened.

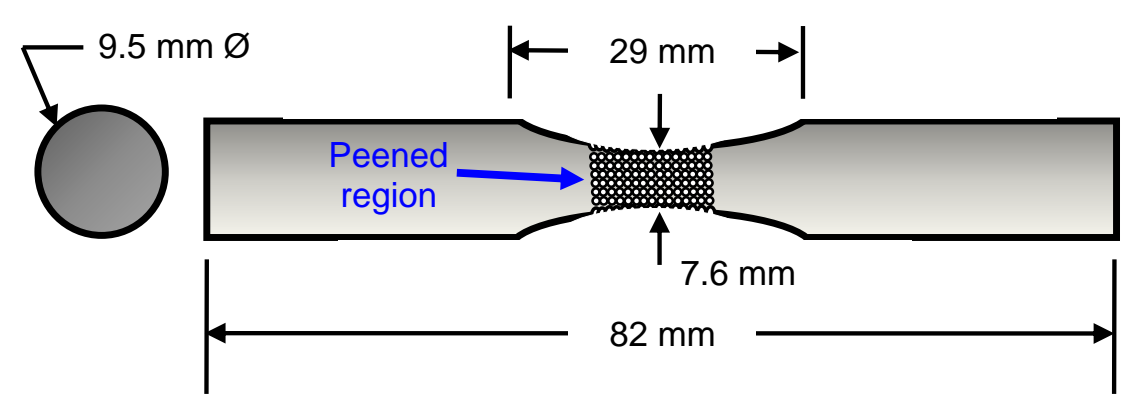

Fig. 6 Fatigue sample geometry.

Fig. 7 shows the experimental setup to fabricate micro dents via laser shock peening (LSP) on the cylindrical surface of MgCa samples. A Continuum Surelite I30 Nd:YAG laser [wavelength $(\lambda) 1064 \mathrm{~nm}$, pulse width $(\tau) 5-7 \mathrm{~ns}$, frequency $(q) 30 \mathrm{~Hz}$ ] with an average power $\left(P_{A V G}\right)$ of $3 \mathrm{~W}$ was used in the experiments. A beam splitter was used to discard some of the energy into a beam dump. The estimated spot diameter was approximately $600 \mu \mathrm{m}$ using a $100 \mathrm{~mm}$ focal length lens. The actual distance between the lens and sample was approximately $90 \mathrm{~mm}$. The cross-sectional area of the laser spot $(A)$ was $0.283 \mathrm{~mm}^{2}$. The corresponding power density $(I)$ was calculated based on Eq. 1 and was approximately $5 \mathrm{GW} / \mathrm{cm}^{2}$. At this power density, the resulting individual dent diameter was $1.390 \mathrm{~mm}$. 


$$
I=\frac{P_{A V G}}{A \cdot \tau \cdot q}
$$

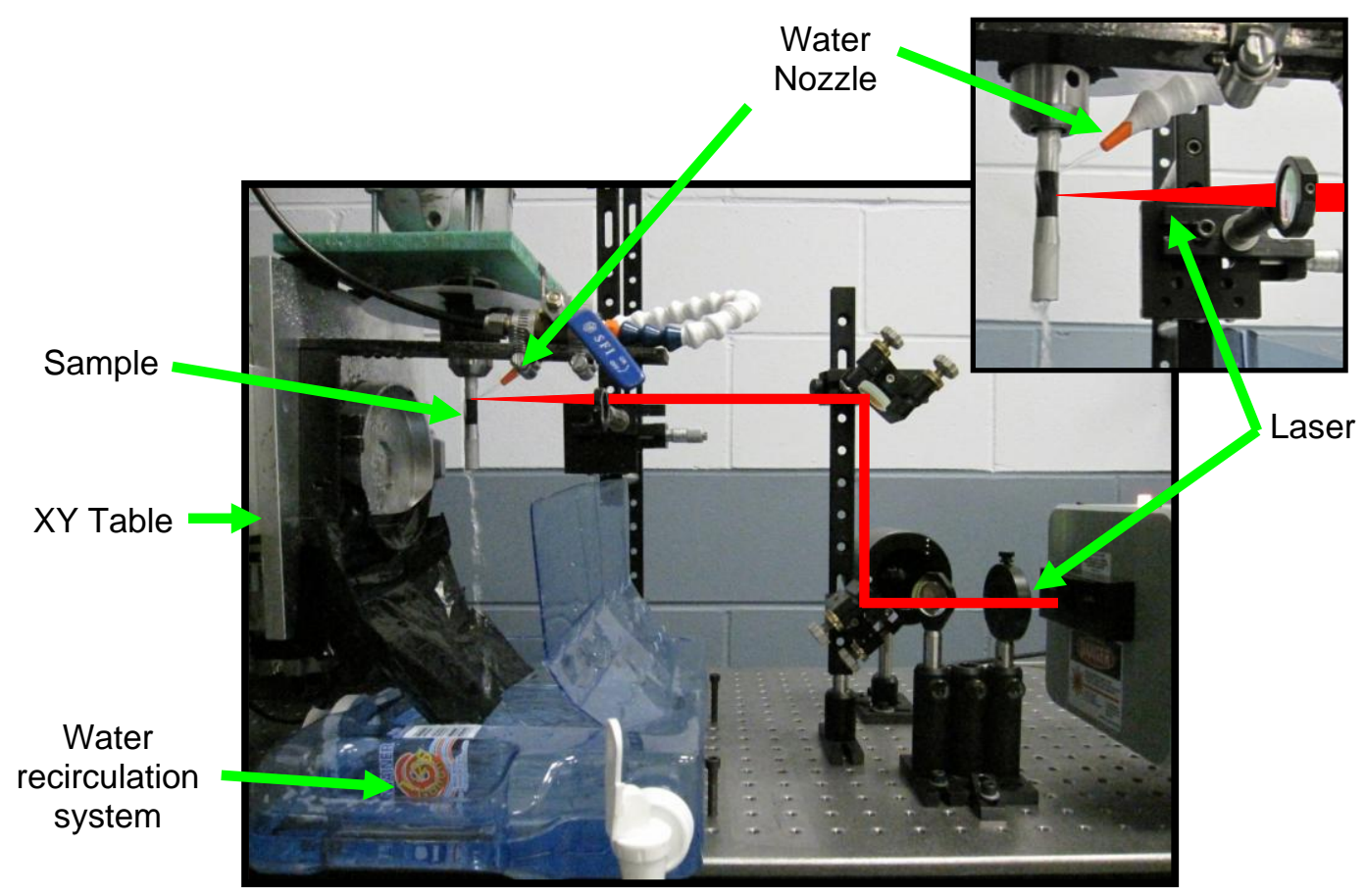

Fig. 7 Experimental setup for laser shock peening cylindrical fatigue samples.

An overlap ratio is defined as the percentage of spatial overlap to the diameter between neighboring dents. For example, a $50 \%$ overlap ratio indicates a dent overlays half of its neighboring dent; a 100\% overlap ratio would be peening the same location twice. The effect of overlap ratio was investigated to determine if micro-dents produced by laser shock peening act as notches that shorten fatigue life or if the compressive residual stress and microhardness act to prevent crack initiation and retard crack propagation. Two dent overlap ratios were studied: $25 \%$ and $75 \%$. To achieve an overlap ratio of $25 \%$ and $75 \%$ on a curved surface, the angular feed $(\gamma)$ in degrees was calculated based on Eq. 2 to precisely rotate the sample. $C$ is the circumference of the fatigue sample which was approximately $24 \mathrm{~mm}$ in the center of the bar. The axial feed $(f)$ is the center-to-center spacing between dents, see Fig. 8. The axial feed was determined by 
measuring the dent diameter $(D)$ produced when $P_{A V G}=3 \mathrm{~W}(1.390 \mathrm{~mm})$ and subtracting that from the overlap distance $(\delta)$, see Eq. 3. The overlap distance is the length that one dent overlaps the next in a matrix and is based on the designed overlap ratio and dent diameter in Eq. 4 . Thus, $f$ was $1.067 \mathrm{~mm}$ and $0.356 \mathrm{~mm}$, and $\gamma$ was $15.14^{\circ}$ and $5.35^{\circ}$ for $25 \%$ and $75 \%$ overlap, respectively. For simplicity, the angular feeds were rounded to the nearest degree, which was $15^{\circ}$ and $5^{\circ}$. The radial dial shown in Fig. 9 was used to rotate the sample to the appropriate angle.

$$
\begin{aligned}
& \gamma=\frac{f}{C} 360^{\circ} \\
& f=D-\delta
\end{aligned}
$$

$$
\delta=(\% \text { Overlap }) \times D
$$
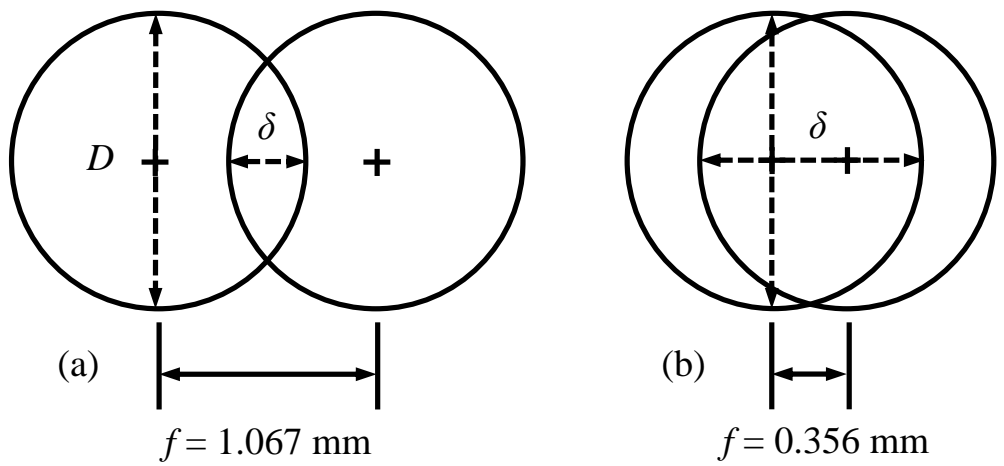

Fig. 8 Schematic of feed $(f)$ and overlap distance $(\delta)$ : (a) 25\%; (b) 75\% overlap ratios $(\delta / D)$. 


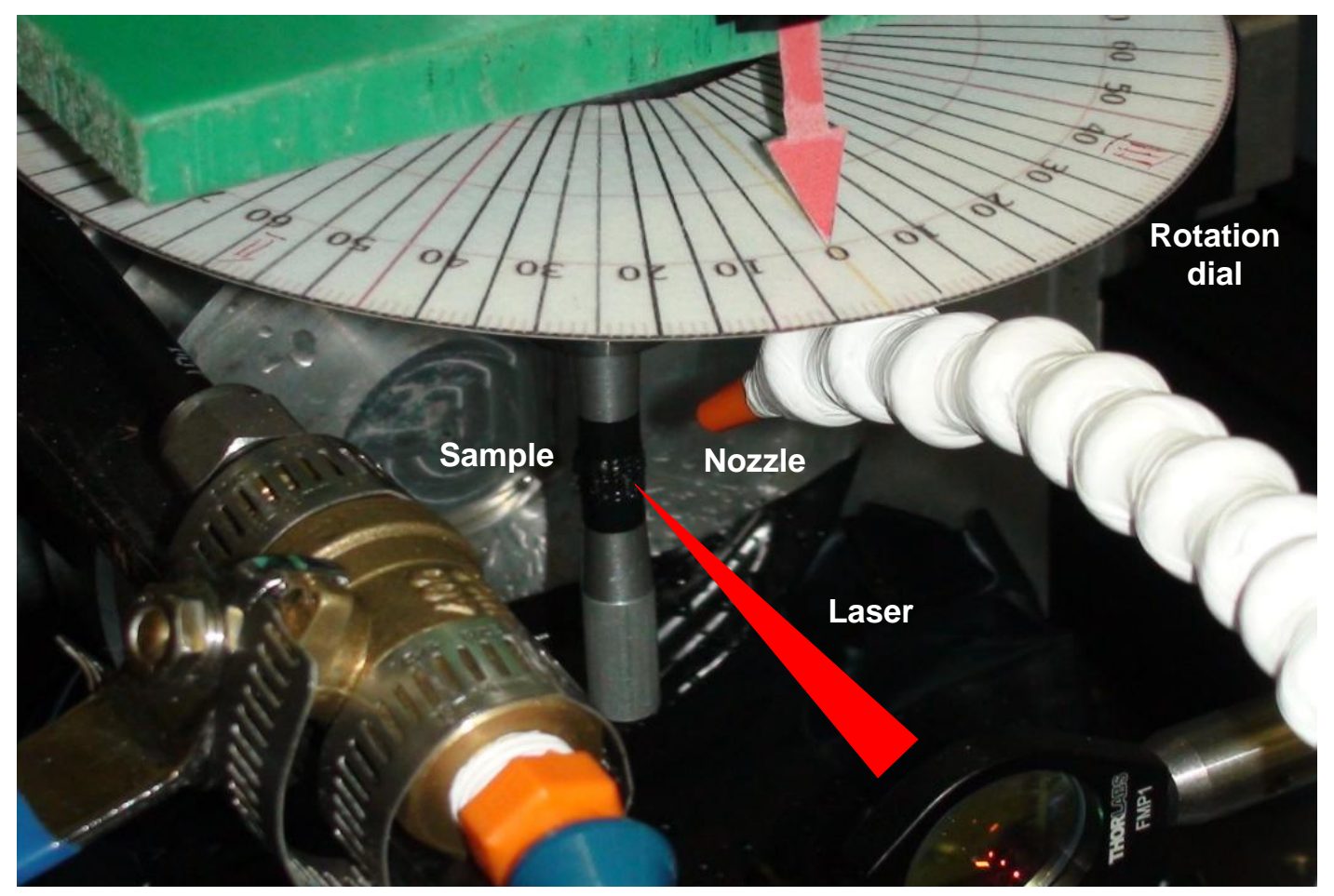

Fig. 9 Radial dial used to rotate the fatigue sample during radial LSP.

Each experiment was performed in vertical water confined regime (WCR) at a depth of approximately $2 \mathrm{~mm}$. The water is allowed to flow over the peened surface as opposed to being static. Flowing water is favorable due to the decreased possibility of particulate interfering with the laser/plasma interface. Black tape was used as the ablative medium. The tape had a thickness of $50 \mu \mathrm{m}$.

\section{Surface Integrity}

\subsection{Topography}

The surface topography of an orthopedic implant is critical for in vivo performance [19, 20]. Every implant requires a specific surface structure which is favorable to the healing process. The surface structure can alter bone's response and fixation. Depending on an implant's application, a unique surface structure can be fabricated using LSP that proactively supports 
healing. By varying the feed, surface parameters such as roughness, peak height, and depth are controllable. However, the topography produced by LSP can act as notches that may shorten fatigue life. Therefore, it is important to quantify basic surface properties in this paper. Refer to Sealy and Guo, 2011 [21] for topography measurement procedures and a more detailed analysis on the effects of LSP on the topography of a MgCa medical device.

The resulting surfaces after laser shock peening cylindrical fatigue samples as well as an unpeened (as-turned) sample are presented in Fig. 10. Data on the roughness, height, depth, and amplitude is presented in Table 1. A 2D topography profile is shown in Fig. 11. The surface roughness $\left(R_{a}\right)$ of a flat unpeened sample was $0.15 \pm 0.07 \mu \mathrm{m}$.

Table 1 Surface Topography after LSP at $3 \mathrm{~W}$ with $25 \%$ and $75 \%$ Overlap Ratios

\begin{tabular}{lllrr}
\hline & & & $3 \mathrm{~W}-25 \%$ & $3 \mathrm{~W}-75 \%$ \\
\hline Surface Roughness & $R_{a}$ & $(\mu \mathrm{m})$ & $2.7 \pm 0.6$ & $6.3 \pm 1.5$ \\
Valley Depth & $R_{v}$ & $(\mu \mathrm{m})$ & $-13.8 \pm 3.1$ & $-14.8 \pm 2.1$ \\
Peak Height & $R_{p}$ & $(\mu \mathrm{m})$ & $1.4 \pm 1.1$ & $0.0 \pm 3.7$ \\
Mean Amplitude & $R_{c}$ & $(\mu \mathrm{m})$ & $15.1 \pm 3.0$ & $14.8 \pm 3.9$ \\
\hline
\end{tabular}

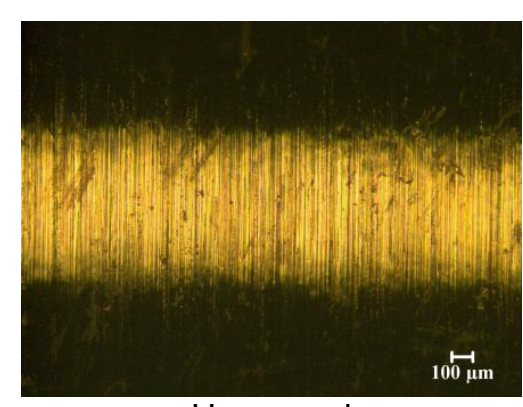

Unpeened

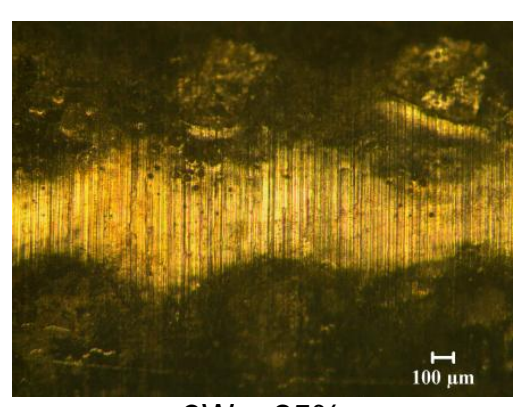

$3 W-25 \%$

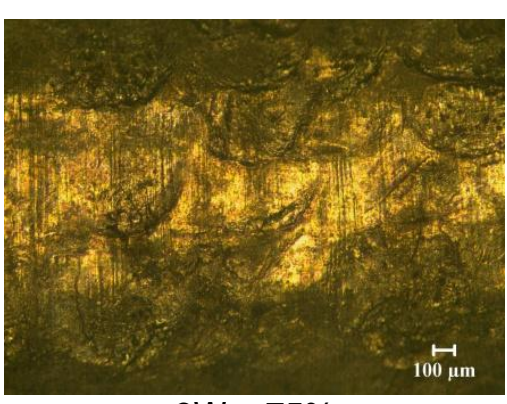

$3 W-75 \%$

Fig. 10 Unpeened and laser peened surfaces of $\mathrm{MgCa} 0.8$. The average laser power was $3 \mathrm{~W}$ and the dent overlap was $25 \%$ and $75 \%$. 


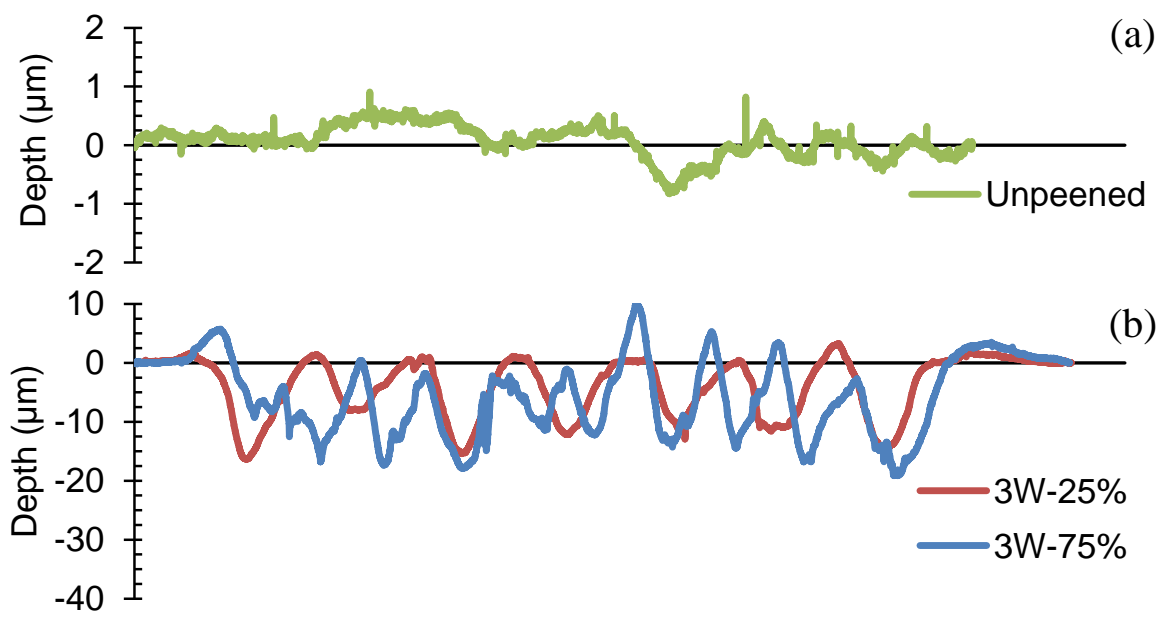

Fig. 11 2D surface topography of (a) unpeened and (b) laser shock peened MgCa.

\subsection{Microhardness}

Hardness is a material's resistance to deformation by indentation [22, 23]. It is a quantitative approach to compare strengths of different materials by measuring the size of an indent. Hardness increases from surface treatments such as LSP due to work hardening. The properties and performance of a work hardened surface such as strength, fatigue life, wear resistance, and corrosion resistance are enhanced significantly [1, 22-24]. Studying microhardness is important since it is unknown if LSP decreases fatigue life via imparting notches or increases fatigue life via enhancing microhardness and imparting compressive residual stress. More information on measurement procedure for microhardness can be found in Sealy and Guo, $2011[21]$.

Vickers microhardness data is presented in Fig. 12. On the top surface, the microhardness was $42.6 \pm 4.7,51.3 \pm 8.0$, and $92.6 \pm 6.7 \mathrm{VHN}$ for unpeened, $3 \mathrm{~W}-25 \%$, and $3 \mathrm{~W}-75 \%$, respectively. At a $75 \%$ overlap ratio, the maximum microhardness shifted from the subsurface to 
the top surface. Also, the microhardness at $75 \%$ overlap extended deeper into the subsurface. The harder surface is attributed to the repeated peening for a given location.

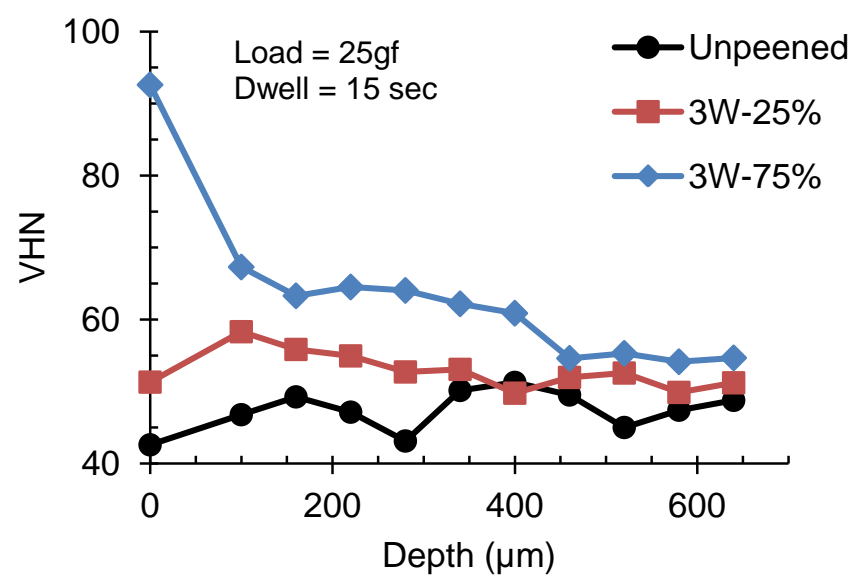

Fig. 12 Vickers microhardness profiles in the subsurface.

\subsection{Residual Stress}

Analogous to microhardness, residual stress is another critical surface integrity factor that can influence fatigue life. The ability of surface treatments such as LSP, shot peening, and burnishing to impart a compressive residual stress on a magnesium alloy has been documented in literature [1, 24-27]. The magnitude of the residual stress can reach $-150 \mathrm{MPa}$ and extend $0.5 \mathrm{~mm}$ into the subsurface. It is important to determine if a compressive residual stress coupled with an increased microhardness can increase fatigue life or do notches overcome any beneficial mechanical improvements from the surface treatment. Future studies will focus on the relationship between residual stress and fatigue life. 


\section{Fatigue Test}

A tensile test of and unpeened $\mathrm{MgCa} 0.8$ sample was conducted to determine a suitable load to apply during the fatigue test. The stress strain response is presented in Fig. 13. The displacement rate was $3.81 \mathrm{~mm} / \mathrm{min}(0.15 \mathrm{in} / \mathrm{min})$. The geometry of the sample is shown in Fig. 6. The ultimate tensile strength was approximately $85 \mathrm{MPa}$. The $0.2 \%$ offset yield strength is approximately $22 \mathrm{MPa}$ and the elastic modulus is $45 \mathrm{GPa}$.

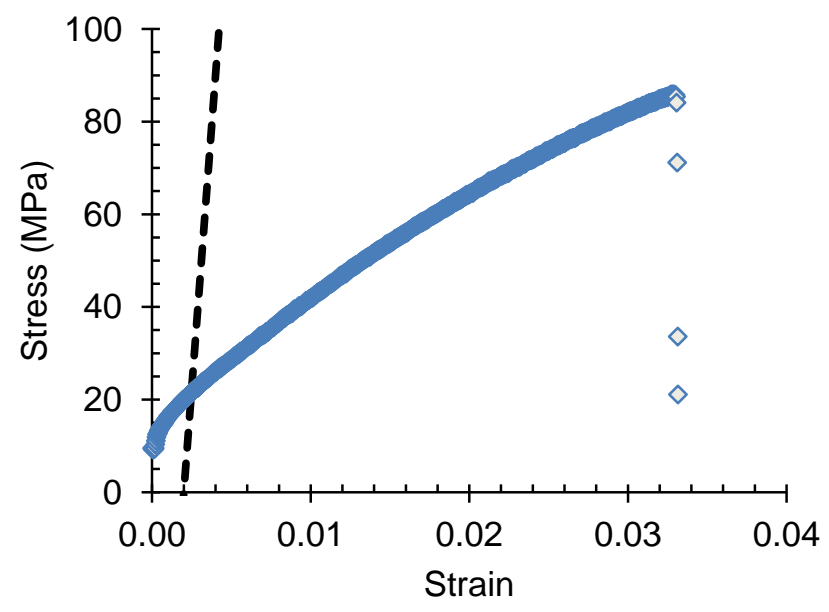

Fig. 13 Stress-strain response of $\mathrm{MgCa} 0.8$ in a tension test.

The aim of this study was to determine if there is a measurable difference between the fatigue life of an unpeened and laser peened sample. An R.R. Moore rotating bending fatigue test was conducted on unpeened and laser shock peened $\mathrm{MgCa} 0.8$ cylindrical samples in air. Rotating bending is ideally suited to test the effect of surface treatments on fatigue performance since the maximum stress from bending occurs on the outer surface. The fatigue test equipment is shown in Fig. 14(a). 


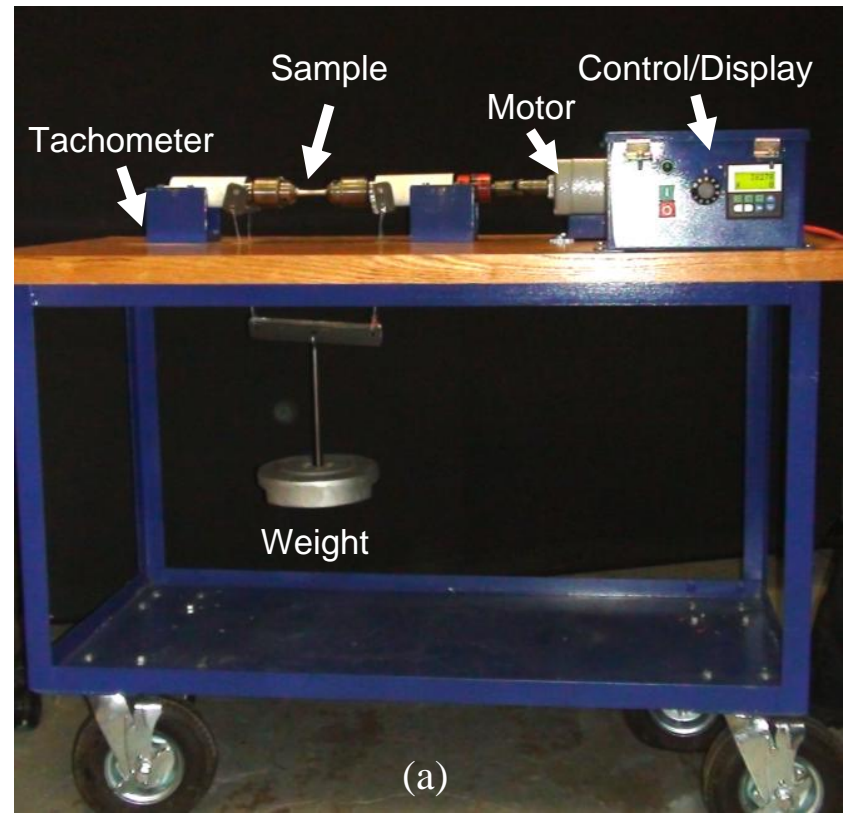

Free body diagram:

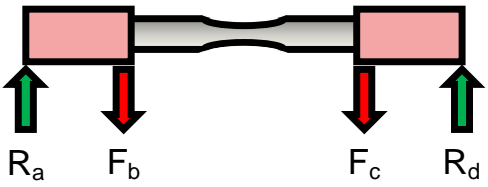

Shear diagram:

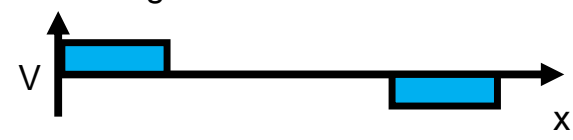

Moment diagram:

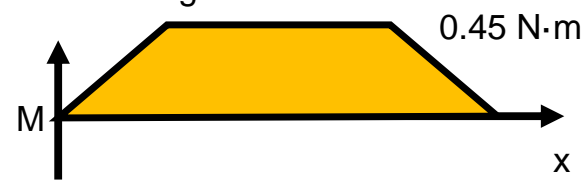

(b)

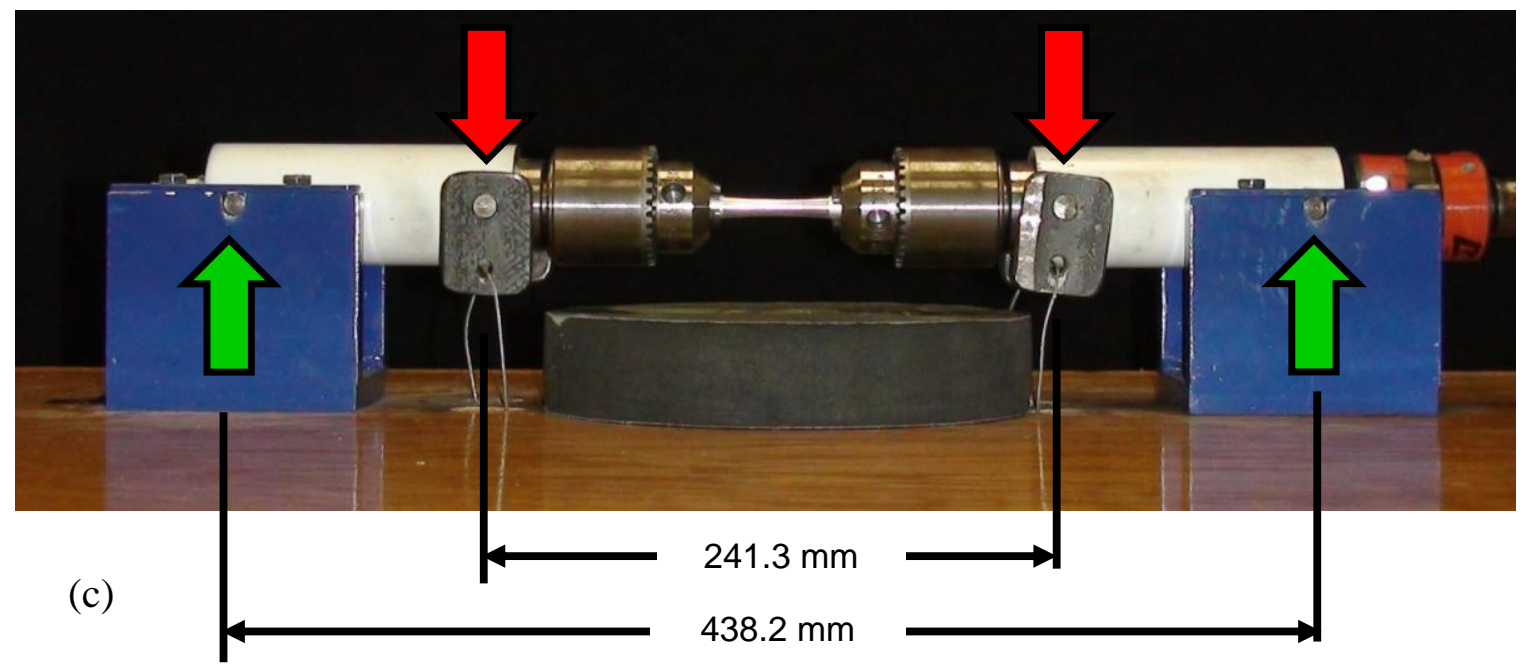

Fig. 14 R.R. Moore rotating bending fatigue test: (a) testing equipment, (b) load diagrams, and (c) equipment dimensions.

There were two groups of samples: peened vs. unpeened. For the peened samples, two levels of peening ratios (25\% and $75 \%)$ were used. At least three fatigue tests were performed for each type of sample. A tachometer was used to monitor rotation speed and count cycles. The frequency was approximately $30 \mathrm{~Hz}$. The applied weight was approximately $0.9 \mathrm{~kg}$ (2 lbs) which corresponded to a bending stress of $10 \mathrm{MPa}$. The bending stress was calculated based on Eq. 5 , 
where $M$ is the bending moment in $\mathrm{N} \cdot \mathrm{m}, y$ is the distance between the neutral axis and the point of interest, and $I_{N A}$ is the moment of inertia with respect to the neutral axis. In rotating bending fatigue tests, the load is fully reversed $(\mathrm{R}=-1)$, the shear force is zero, and the bending moment across the sample is constant as shown in Fig. 14(b). The dimensions of rotating bending fatigue test equipment are shown in Fig. 14(c).

$$
\sigma=\frac{M y}{I_{N A}}
$$

Assumptions regarding the fatigue test are as follows:

- Samples were uniformly laser shock peened.

- The grain size $(100-700 \mu \mathrm{m})$ has a negligible effect on fatigue life compared to the effect from the LSP surface treatment. Since large grains are known to shorten fatigue life, the results must be statically different in order to ensure it is the surface treatment that causes an improvement in fatigue life.

- The chucks are aligned such that there is no pre-stress from misalignment. Misalignment can lead to premature failure.

- The weight of the chucks pre-stressed all samples consistently. The weight of the chucks added an extra load that was not included in the reported applied load.

- Samples were uniformly tightened in the chucks in a manner that prevented slipping during testing. Uniformly tightening the samples ensures the sample are under identical stress states at the grips.

\section{Fatigue Life and Characterization}


The fatigue life of unpeened and laser shock peened $\mathrm{MgCa}$ is presented in Fig. 15. The error bars represent the range of the measured data. Laser shock peening was found to increase the fatigue life by at least 1 order of magnitude. The average fatigue life of an unpeened and laser peened sample was 5,325 cycles and 122,620 cycles, respectively. The results show $75 \%$ peening overlap produced a longer fatigue life than $25 \%$ overlap.

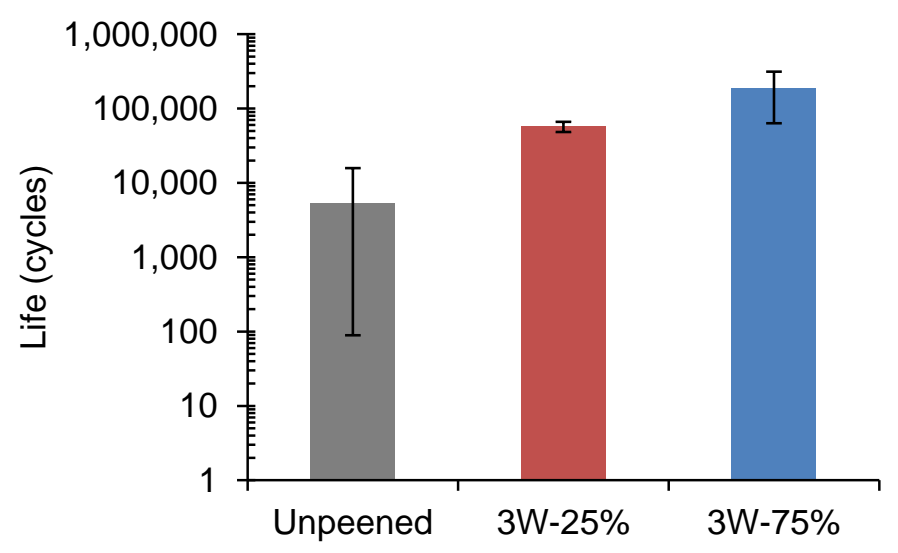

Fig. 15 Rotating bending fatigue life of unpeened vs. laser peened MgCa samples.

The fractured samples are shown in Fig. 16. The unpeened and 3W-25\% samples failed in the center; however, the samples at $75 \%$ overlap failed just outside the peened region. The results indicated that the increase in hardness and compressive residual stress were able to overcome any notch sensitivity effect caused by the peening process. 


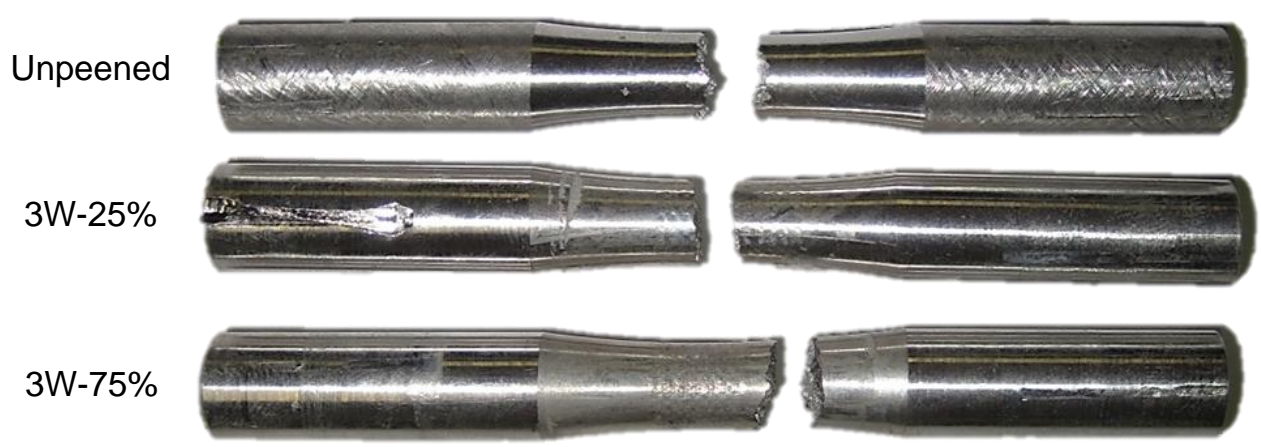

Fig. 16 Fatigue samples after fracture.

The fractured surfaces are presented in Fig. 17. The unpeened samples exhibited fast granular fracture. No striation patterns were observed. On the other hand, the peened samples did exhibit striation patterns. Samples with longer fatigue lives, i.e. 3W-75\%, exhibited a more pronounced pattern. The demarcation between the crack growth region and fast fracture region was clearly distinguishable for $3 \mathrm{~W}-75 \%$. A higher resolution image of the crack propagation region is presented in Fig. 18.
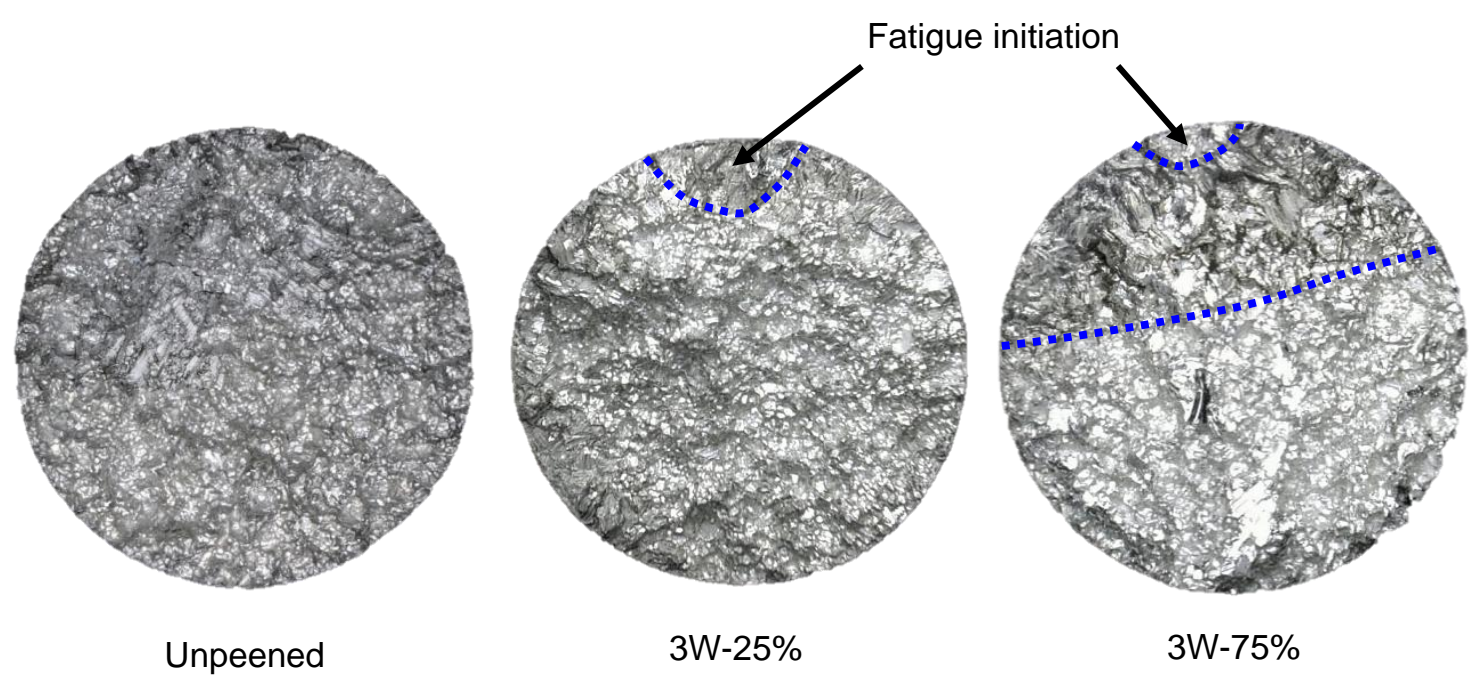

Fig. 17 Optical image at $100 \times$ of a fractured $\mathrm{MgCa}$ surface after rotating bending fatigue tests. 


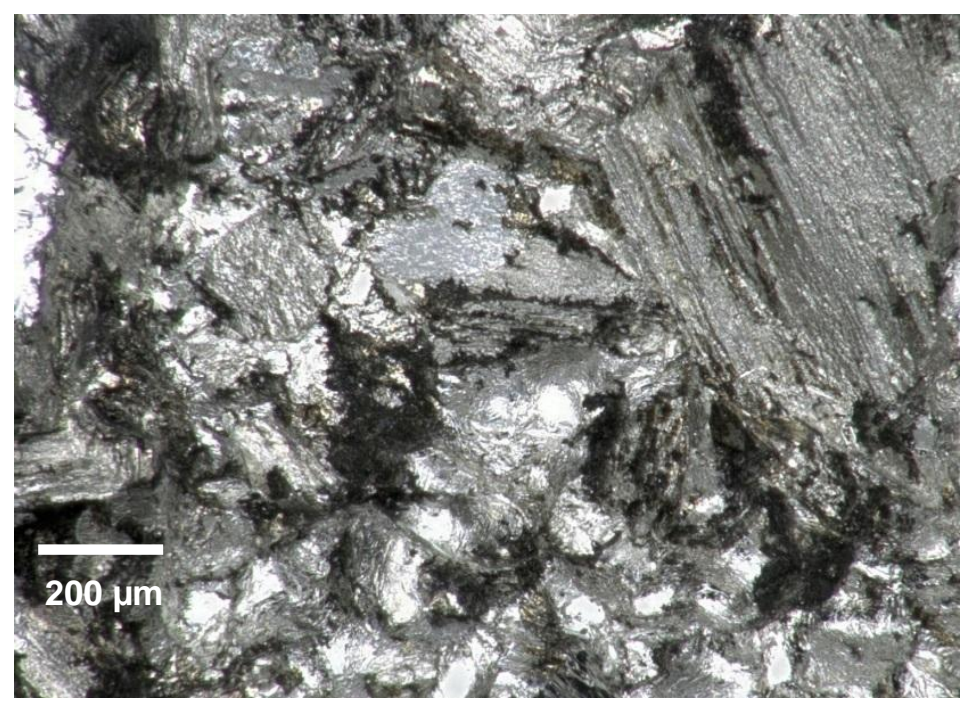

Fig. 18 Fractured surface's crack growth region (LSP at 3W-75\%).

\section{Conclusions}

Laser shock peening of a biodegradable $\mathrm{MgCa} 0.8$ alloy was initiated to adjust surface integrity that improves the fatigue performance of orthopedic implants. Sequential laser peening at different overlap ratios was performed to determine the effects on fatigue performance. Since the sample size was small in this study, only the tendencies can be reported. It should also be noted that the results are only valid for the given load conditions and may not be generalized. Key conclusions are summarized below.

- Laser shock peening can improve the fatigue life of $\mathrm{MgCa}$ implants under the conditions used in this study.

- Micro-dents produced during the peening process did not act like notches that concentrate the stress and cause premature failure. Thus, it is concluded that the compressive residual stress and increased microhardness are able to overcome notch sensitivity effects.

- A higher peening overlap ratio improved the fatigue performance such that fracture occurred outside the peened region. 
- The unpeened samples underwent brittle "fast" fracture and exhibited little or no plasticity. The peened samples exhibited a region of fatigue crack propagation (striation pattern), and it was more pronounced at higher overlap ratios.

\section{Acknowledgments}

This research is based upon the work supported by NSF under Grant No. CMMI-1000706 as well as the Department of Education's GAANN fellowship. 


\section{References}

[1] Guo, Y., Sealy, M. P., Guo, C., 2012, "Significant Improvement of Corrosion Resistance of Biodegradable Metallic Implants Processed by Laser Shock Peening," CIRP Annals Manufacturing Technology, 61(1) pp. 583-586.

[2] Barkey, M., 2008, "Introduction to Fatigue," AEM 649 - Fatigue Analysis Lecture on 8/20/2008, The University of Alabama, Tuscaloosa, AL.

[3] Schijve, J., 2009, "Surface Treatments," Chap. 14, Fatigue of Structures and Materials, Springer Netherlands, pp. 421-436.

[4] Clauer, A.H., Holbrook, J.H., Fairand, B.P., 1981, "Effects of Laser Induced Shock Waves on Metals," Chap. 7, Shock Waves and High-Strain-Rate Phenomena in Metals: Concepts and Applications, Springer US, New York, pp. 675-702.

[5] Clauer, A., 1996, "Laser Shock Peening for Fatigue Resistance," Surface Performance of Titanium, J. K. Gregory, H. J. Rack and D. Eylon, eds. The Metal Society of AIME, pp. $217-230$.

[6] Peyre, P., Fabbro, R., Merrien, P., Lieurade, H. P., 1996, "Laser Shock Processing of Aluminium Alloys. Application to High Cycle Fatigue Behaviour," Materials Science and Engineering: A, 210(1-2) pp. 102-113.

[7] Ruschau, J. J., John, R., Thompson, S. R., Nicholas, T., 1999, "Fatigue Crack Nucleation and Growth Rate Behavior of Laser Shock Peened Titanium," International Journal of Fatigue, 21(Supplement 1) pp. S199-S209.

[8] Nalla, R. K., Altenberger, I., Noster, U., Liu, G. Y., Scholtes, B., Ritchie, R. O., 2003, "On the Influence of Mechanical Surface Treatments - Deep Rolling and Laser Shock Peening on the Fatigue Behavior of Ti-6Al-4V at Ambient and Elevated Temperatures," Materials Science and Engineering: A, 355(1-2) pp. 216-230.

[9] Bannantine, J.A., Comer, J.J., Handrock, J.L., 1990, "Fundamentals of Metal Fatigue Analysis," Prentice-Hall, Upper Saddle River, NJ.

[10] Kannan, M. B., Singh Raman, R. K., Kannan, M. B., Blawert, C., Dietzel, W., 2011, "Influence of Circumferential Notch and Fatigue Crack on the Mechanical Integrity of Biodegradable Magnesium-Based Alloy in Simulated Body Fluid," Journal of Biomedical Materials Research Part B: Applied Biomaterials, 96B(2) pp. 303-309.

[11] Höh, N. V. D., Bormann, D., Lucas, A., Denkena, B., Hackenbroich, C., MeyerLindenberg, A., 2009, "Influence of Different Surface Machining Treatments of Magnesium-Based Resorbable Implants on the Degradation Behavior in Rabbits," Advanced Engineering Materials, 11(5) pp. B47-B54. 
[12] Fouad, Y., 2011, "Fatigue Behavior of a Rolled AZ31 Magnesium Alloy After Surface Treatment by EP and BB Conditions," Alexandria Engineering Journal, 50(1) pp. 23-27.

[13] Fouad, Y., El Batanouny, M., 2011, "Effect of Surface Treatment on Wear Behavior of Magnesium Alloy AZ31," Alexandria Engineering Journal, 50(1) pp. 19-22.

[14] Hilpert, M., Wagner, L., 2000, "Corrosion Fatigue Behavior of the High-Strength Magnesium Alloy AZ 80," Journal of Materials Engineering and Performance, 9(4) pp. 402-407.

[15] Bhuiyan, M. S., Mutoh, Y., McEvily, A. J., 2012, "The Influence of Mechanical Surface Treatments on Fatigue Behavior of Extruded AZ61 Magnesium Alloy," Materials Science and Engineering: A, 549(0) pp. 69-75.

[16] Dindorf, C., Müller, C., 2003, "Corrosion and Fatigue Behaviour of the Magnesium DieCast Alloy AZ91 hp after Surface Treatment," Magnesium, Wiley-VCH Verlag GmbH \& Co., pp. 574-579.

[17] Liu, W. C., Dong, J., Zhang, P., Korsunsky, A. M., Song, X., Ding, W. J., 2011, "Improvement of Fatigue Properties by Shot Peening for Mg-10Gd-3Y Alloys Under Different Conditions," Materials Science and Engineering: A, 528(18) pp. 5935-5944.

[18] Zinn, W., Scholtes, B., 1999, "Mechanical Surface Treatments of Lightweight Materials Effects on Fatigue Strength and Near-Surface Microstructures," Journal of Materials Engineering and Performance, 8(2) pp. 145-151.

[19] Breme, J., Kirkpatrick, C.J., Thull, R., 2008, "Metallic Biomaterial Interfaces," WileyVCH Verlag GmbH \& Co. KGaA, Weinheim, FRG, pp. 252.

[20] Kieswetter, K., Schwartz, Z., Dean, D. D., Boyan, B. D., 1996, "The Role of Implant Surface Characteristics in the Healing of Bone," Critical Reviews in Oral Biology \& Medicine, 7(4) pp. 329-345.

[21] Sealy, M. P., Guo, Y. B., 2011, "Fabrication and Characterization of Surface Texture for Bone Ingrowth by Sequential Laser Peening Biodegradable Orthopedic MagnesiumCalcium Implants," ASME Journal of Medical Devices, 5(1) pp. 1-9.

[22] Groover, M.P., 1996, "Fundamentals of Modern Manufacturing: Materials, Processes, and Systems," Prentice-Hall, New Jersey, pp. 1061.

[23] Schey, J.A., 2000, "Introduction to Manufacturing Processes," McGraw-Hill, pp. 962.

[24] Denkena, B., Lucas, A., 2007, "Biocompatible Magnesium Alloys as Absorbable Implant Materials Adjusted Surface and Subsurface Properties by Machining Processes," CIRP Annals - Manufacturing Technology, 56(1) pp. 113-116. 
[25] Salahshoor, M., Guo, Y. B., 2011, "Surface Integrity of Biodegradable MagnesiumCalcium Orthopedic Implant by Burnishing," Journal of the Mechanical Behavior of Biomedical Materials, 4(8) pp. 1888-1904.

[26] Zhang, P., Lindemann, J., Leyens, C., 2010, "Shot Peening on the High-Strength Wrought Magnesium Alloy AZ80 - Effect of Peening Media," Journal of Materials Processing Technology, 210(3) pp. 445-450.

[27] Sealy, M. P., Guo, Y. B., 2010, "Surface Integrity and Process Mechanics of Laser Shock Peening of Novel Biodegradable Magnesium-calcium (Mg-Ca) Alloy," Journal of the Mechanical Behavior of Biomedical Materials, 3(7) pp. 488-496. 


\section{Graphical Abstract}

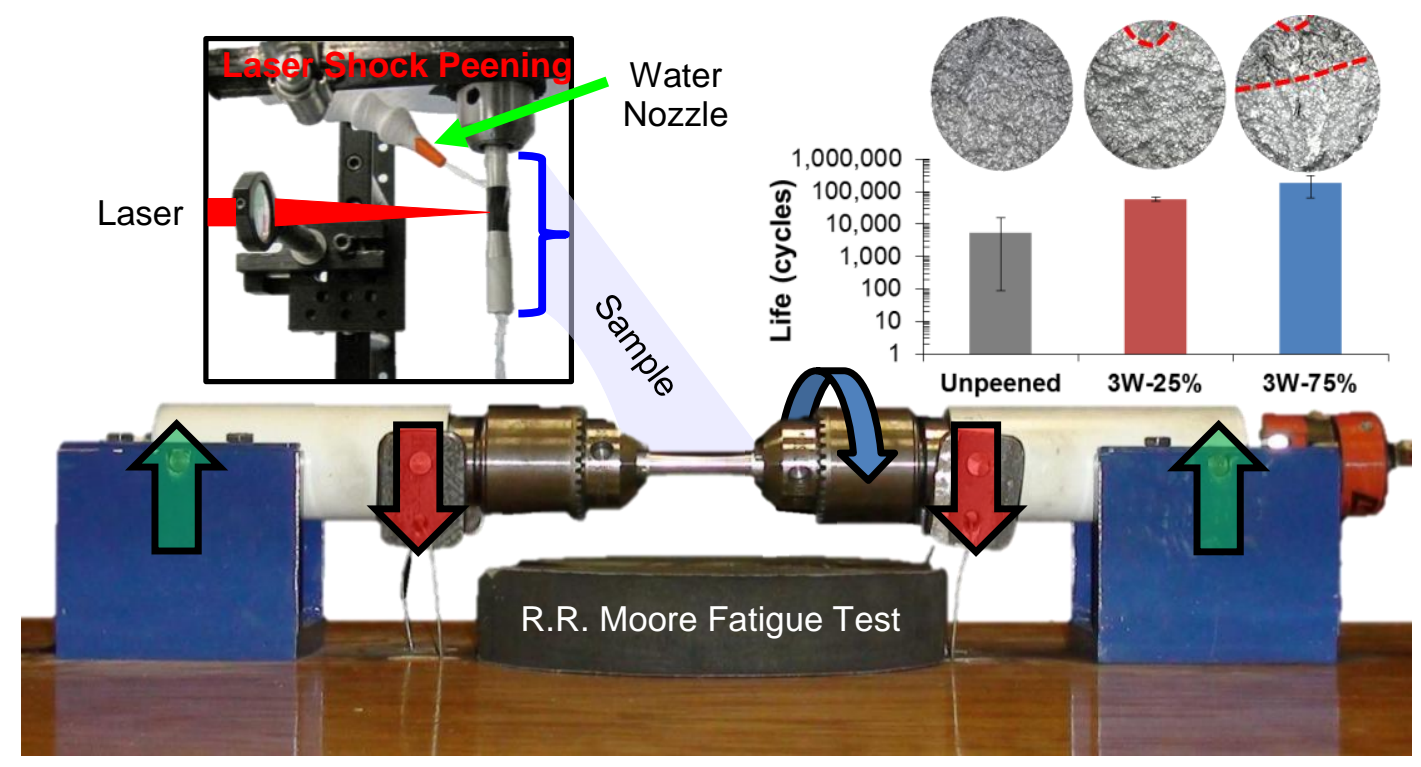

